
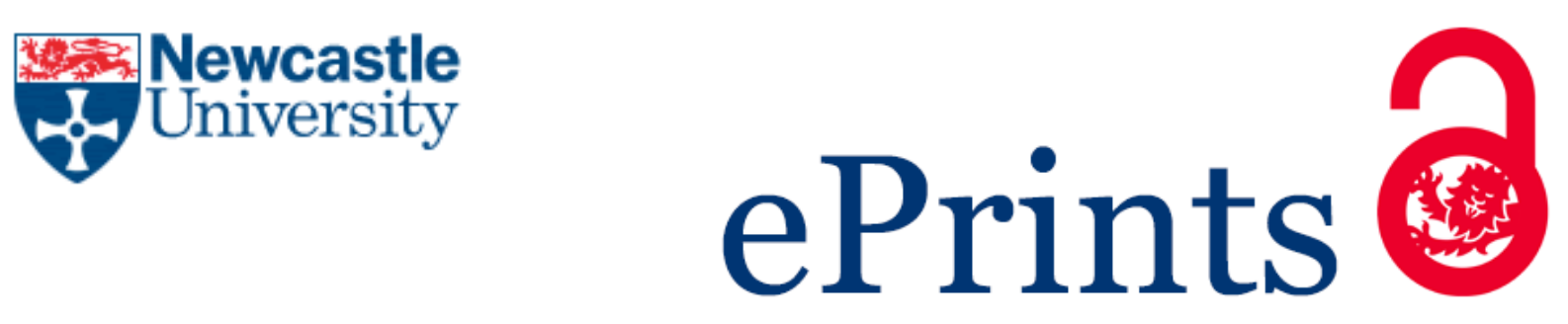

Hazel S, Wagner J.

L2 and L3 Integrated Learning: Lingua Franca Use in Learning an Additional

Language in the Classroom.

In: Jenks CJ; Seedhouse P, ed. International Perspectives on the ELT classroom interaction. Basingstoke, UK: Palgrave MacMillan, 2015, pp.149-167.

\title{
Copyright:
}

(C) Spencer Hazel and Johannes Wagner 2015 reproduced with permission of Palgrave Macmillan. This extract is taken from the author's original manuscript and has not been edited. The definitive, published, version of record is available here: https://doi.org/10.1057/9781137340733 9 and

www.palgraveconnect.com

DOI link to article:

https://doi.org/10.1057/97811373407339

Date deposited:

$12 / 10 / 2017$

Embargo release date:

05 May 2018 
Spencer Hazel

Roskilde university

spencer@ruc.dk (corresponding author)

Johannes Wagner

University of Southern Denmark

jwa@sdu.dk

\section{L2 and L3 integrated learning - lingua franca use in learning an additional language in the classroom}

\section{Introduction}

This study offers an empirical account of the use of English in Danish-as-a-foreign-language classroom settings. We will refer to English as the lingua franca - which in itself is a second language for the majority of the participants in the data - and to Danish as the target language. We consider implications of lingua franca interaction in target language classroom interactions, and show how in sequences where participants orient to linguistic issues in the target language, for example grammatical forms or lexical items, they often do this with reference to the lingua franca.

Foreign and second language classroom settings where English is used as a lingua franca have been described for other target languages and other geographic areas. For example, Lee \& Ogi (2013) have studied the use of English in Japanese-as-a-foreign-language courses in Australia, where a growing proportion of students attend from countries where English is not a first or official language. Elsewhere, Wang (2013) describes how with the burgeoning demand for Chinese-as-aforeign-language, one basic requirement in the recruitment of qualified teachers to the profession is a command of English (or one of the other major languages). Both these studies use interview data to investigate teacher and learner attitudes to the use of a lingua franca in these language classroom settings. In yet another part of the world, and combining discourse analysis with an autoethnographic approach, Kirkebæk (2013) explores a Danish FL teacher's use of English in the 
classroom. He suggests that in addition to English here being used for pedagogical purposes, including scaffolding and topic development, it also allows teachers to better develop interpersonal relations with their students. In the current study, we follow a Conversation Analytic (CA) approach to a collection of similar action sequences drawn from a data set of Danish FL classrooms at a university in Denmark.

CA studies of L2 classroom interaction have sought to identify practices whereby the organisational make-up of particular interactional sequences allows for language development opportunities in the target language (for example, Hellerman, 2008; Kasper, 2004; Markee 1995, 2000; Markee \& Seo 2009, Eskildsen \& Wagner 2013, forthcoming, Mondada \& Pekarek Doehler, 2004; Mori, 2004; Seedhouse, 2004). Many of these studies have focused on language learning, interaction and competences in the curricular target language of the course. English has in most of these studies either been the target language or the native language of the students. Typically, no other languages were involved. In the current study, we explore a different type of classroom scenario, namely where another language than English is the target language and where a lingua franca is used as a resource in a language classroom. The students in our study come from widely differing sociocultural and linguistic backgrounds, and participants orient to both the target language and the classroom lingua franca as accepted and relevant resources for learning.

The setting featured in the data for the current chapter is a Danish L2 classroom at a Danish university. English is adopted as a lingua franca for much of the interaction, especially in lower level classes (see also Kirkebæk, 2013, for further discussion of this setting). This is similar to other university settings, where students are required to study their curricular subjects through the adoption of English as the medium-of-instruction or medium-of-classroom-interaction (Bonacina \& Gafaranga, 2011). What is different here is that we note an increased presence of sequences that focus on linguistic issues of the target language, that often are negotiated in the lingua franca. This 


\section{Late draft}

leads to the intriguing question whether the Danish L2 language classrooms are settings where the students not only develop their English language competences with regard usage (focus-onfluency), but where in addition they are required to attend to their explicit knowledge of English, especially relating to form-focused competences.

In the data, the teachers cross-reference between Danish and English in order to facilitate sequences where there is a focus on form, accuracy and/or meaning in the target language (see Seedhouse, 2004), in addition to assisting in classroom interaction management, and promoting teacher-student rapport (Kirkebæk, 2013). English offers the participants an alternative medium-for-classroominteraction and instruction (Bonacina \& Gafaranga, 2011), and is employed as a resource for clarifying linguistic forms in the target language. To do so, however, classroom participants must have, and demonstrate, sufficient competence in the lingua franca to fruitfully draw out such linguistic associations, or utilize the lingua franca in facilitating interaction. This involves teachers being sensitive to their students' varying levels of proficiency in the lingua franca to sufficiently utilize it as such a resource. In addition, we hope to present enough evidence to argue that these practices, occasioned to aid comprehension of the target language, also offer students opportunities for developing their proficiency in the lingua franca.

A growing body of educational research has investigated the implications of studying curriculum subjects in or through an additional language. Here, educational programmes adopt a joint pedagogical focus, one which allows students to develop their competences in a target language while at the same time carrying out their regular curricular course work. The majority of research into this type of classroom has featured overwhelmingly non-language subjects such as history, computer science, religion, geography and technology (for one overview, see Lasagabaster, 2008) as the curriculum content part of the course. The research reported in the current chapter draws on a different type of content topic: Danish-as-an-additional-language, as offered to non-Danish 
Late draft

students at a Danish tertiary level institution. Here, although the language to be learned constitutes both the topic and often also medium of instruction, teachers and students from a wide range of linguistic backgrounds also draw on English lingua franca competences.

\subsection{Background to the study}

The current study reports from a Northern European, and more specifically a Danish context, and was carried out under the auspices of the Research Centre for Cultural and Linguistic Practices in the International University (CALPIU) ${ }^{1}$. CALPIU was established to investigate the processes of internationalization to which Higher Education institutions and the actors in these communities are subject (see Knight, 2004; Haberland et al., 2008; Preisler et al, 2008). The research network constitutes a 'convergent diversity' of researchers (Goodwin, 1995) interested in examining the issues and processes connected with such transnational student and staff mobility, with researchers representing different strands of social scientific research, including various (applied) linguistic fields, sociology, ethnomethodological conversation analysis, and ethnography. The collaboration has sought to explore four areas of practice within internationalizing university settings: 1 . the communicative practices and self-conception of the university as an actor in the multilingual world; 2. student-teacher interactions; 3. student-student interactions; and 4. student-administrative staff interactions. The current study focuses on classroom interaction in L2 Danish instruction.

Transnational student mobility has gained strongly in momentum in the last couple of decades. OECD (2012) has reported a fivefold increase since 1975, with more than 4 million tertiary level students enrolled in courses outside of their home countries in 2010. This growth has accelerated over the course of this period, reflecting both the processes of social and economic globalization, as well as levels of tertiary level enrolment. Between the years 2000 and 2010, for example, the numbers of students enrolled at institutions away from their home countries doubled. Although

1 see calpiu.dk 
students have been seen traditionally to mostly follow what has been described as historical, postcolonial paths from 'East' to 'West' and also from non-English speaking to English-speaking nations (Waters \& Brooks, 2012), recent developments point to shifts in the direction of the flow of movement, with evidence of an emergent differentiation in the Higher Education market (Brooks, Fuller \& Waters, 2012). For example, the most popular destination for students travelling on the EU-run ERASMUS programme for European students in 2010-2011 was Spain, followed by France, Germany, the United Kingdom and Italy (European Commission, 2012a).

Within the European Union (EU), transnational student mobility has received a great deal of institutional support at national and international levels since the 1980s. Students may choose to pursue their entire tertiary education at a foreign institution, or may alternatively choose to participate in shorter exchange programmes, such as the EU-sponsored ERASMUS programme ${ }^{2}$, a flagship of the EU's lifelong learning programme ${ }^{3}$. Figures show that in excess of 2.5 million students have travelled to one of 4000 institutions in 33 countries since 1987 on this exchange programme, with the length of a student's sojourn on an Erasmus exchange being between 3-12 months (European Commission, 2012a). The institutional aims of the ERASMUS framework relate to supporting the development of a "well-qualified, open-minded and internationally experienced" pool of future professionals (European Commission, 2012a: 3), in turn contributing to EU citizens' personal development, and supporting European economic and societal well-being (ibid.). In addition, cross-border inter-institutional co-operation is promoted, with the resulting enrichment of the education environments at these institutions. At a more personal level, such study periods abroad are increasingly considered important opportunities for promoting knowledge of other

\footnotetext{
2 The ERASMUS programme is also available to support work placements in companies.

3 This also includes the Comenicus programme for schools; the Leonardo da Vinci programme for vocational training; and the Grundtvig programme relating to adult education.
} 


\section{Late draft}

cultures and languages, providing students with vital experience for further career opportunities (European Commission, 2012b).

Regarding this final point, the promotion of knowledge of other cultures and languages, it may appear somewhat ironic that the waves of internationalisation that have been implemented across Higher Education have been premised on the widespread adoption of a single language, English, to serve as a lingua franca, not least in non-Anglophone countries such as those in Scandinavia (see Mortensen \& Haberland, 2012). Indeed, the opportunity to improve one's English competences is trumpeted as a core benefit afforded students on such study exchange periods. In line with this, institutions have increasingly opted to offer English-medium courses to attract non-local students; marketing materials have are produced in combinations of local language and English versions; and administrative support is being increasingly also offered in English (see Hazel, 2012). As a result, institutional requirements themselves now stipulate minimum levels of English proficiency as prerequisites for enrolment in study programmes. Increased internationalisation of the make-up of these tertiary level education communities then suggests that it may not lead to increased linguistic diversity in these settings. Indeed, that there is a danger of it resulting in reduced linguistic diversity, as English is afforded an exclusive lingua franca position.

A closer look at the picture, however, allows us to see that this is not uncontested. Any suggestion that a. English is the only additional language international students hope to develop competence in, and b. English is the only language a student needs to live and study in a non-Anglophone country, would be misleading. Many international students indeed demonstrate a keen desire to take up the challenge to engage with the local language, for example taking up language classes, or utilising their new found skills in curricula (see for example, Mortensen, 2014) and non-curricula (Hazel \& Mortensen, 2013) activities and settings. The result of this is that these communities of transnational students, made up of cohorts of students from different parts of the world and diverse 
linguistic backgrounds, may use a variety of linguistic - and indeed non-linguistic - resources as they navigate a path from through constantly fluctuating participation frameworks, their contingent language scenarios (Mortensen, 2010) and situated activities. These may feature, interchangeably, the local language, a lingua franca, be it English or another (for example a Romance or Scandinavian language), one's first language, or any combination of the above.

\subsection{Data and method}

The data for the study is drawn from the CALPIU data storehouse, a large depository of audio and audio-visual data that was recorded in a range of university settings in Denmark. The sub-set of Danish L2 classrooms data include recordings from four levels, ranging from beginner to advanced classes, and included 3 teachers. For the data set, lessons were recorded during the first two weeks of a course module, and again the last two weeks leading up to a module test. The data included in the current chapter is taken from the recordings of a beginner module 1 (equivalent to the Breakthrough (A1) level of The Common European Framework of Reference for Languages), the combined module 2/3 (Waystage/Waystage-Threshold (A2)), and module 4 (Threshold (B21) level in CEFR terms).

The recordings were produced using 3 stationary cameras, in order to cover as large an area as possible in the classroom. One camera was positioned at the back of the space, with two others placed at angles above the blackboard at the front of the class. Additional table-top microphones were placed on each table, and these were supplemented with an extra audio recorder at the front of the class. The data were processed using $\mathrm{ELAN}^{4}$ as a digital annotation tool, with a collection of illustrative extracts subsequently transcribed in $\mathrm{CLAN}^{5}$. Transcription conventions are based on those developed by Gail Jefferson (e.g., 2004). Some are used here in modified form for the benefit

\footnotetext{
${ }^{4}$ ELAN was developed by the Max Planck Institute for Psycholinguistics, Nijmegen, The Netherlands, and is a free software tool that enables digital annotation of video and audio data (http://www.lat-mpi.eu/tools/elan/).

${ }^{5}$ CLAN is a free software tool which among other things allows researchers to produce transcripts with continual linkage between transcript and the audio or video data (http://childes.psy.cmu.edu/clan/).
} 
Late draft

of the CLAN software tool (further explanation provided at the end of the text). The resulting data representations were subsequently analysed using methodological practices developed for Conversation Analysis (Sacks, Schegloff \& Jefferson, 1974).

\section{Data analysis}

In what follows, we will discuss a number of cases that are part of a collection of comparable cases observed in the dataset. The collection is drawn from different modules within the Danish teaching programme, and these will be referred to in the text. In the first section, we focus of how the students' English competences become a resource to facilitate understanding of particular target structures in Danish. This will be followed by a section where we look at the seamlessly produced and highly ordered shifting between target language and lingua franca. Before concluding our argument, we will in a third analytic section we how students are recruited to provide explanations of particular equivalent linguistic forms in English. We will present a number of examples of sequences where participants orient to linguistic issues in the classroom.

\subsection{The relation between target language and lingua franca}

Excerpt 1 is taken from the latter stages of a beginner Module $1^{6}$ course. The teacher has just announced that they will start looking at past tense forms of verbs. As an example, he introduces the verb at blive 'to become'. The medium of instruction at this point is English, which is common in this beginner-level module. In Excerpt 1, the talk is still concerned with he infinitive and present tense forms of the verb.

Excerpt 1 Level: Module 1; TEA teacher; MAR Martin

\footnotetext{
${ }^{6}$ This equates with the Breakthrough (A1) level of The Common European Framework of Reference for Languages (CEFR), (see www.coe.int/lang)
} 


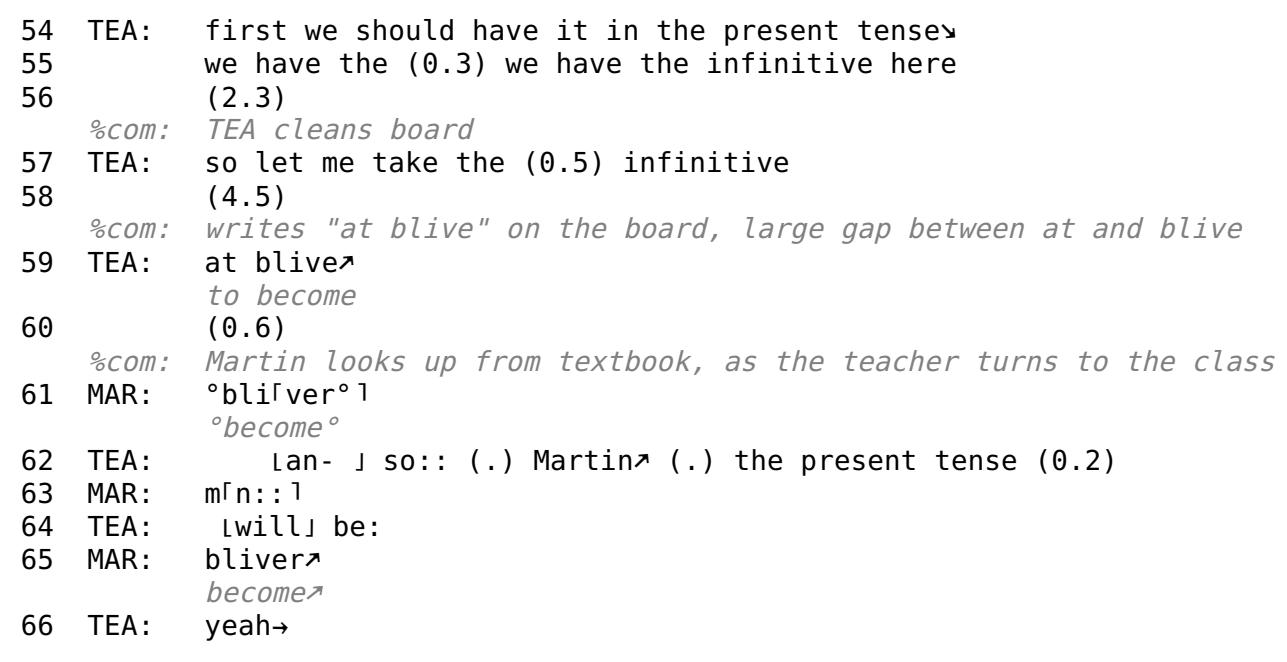

In line 55, the teacher projects to write the verb in its infinitive form, and proceeds to write at blive on the board (lines 57-58). The manner in which he produces the inscription appears to emphasize the shape of the infinitive form, with the at 'to' separated from the blive 'become' with what measures as the equivalent of 3 spaces, rather than a conventional single space separating them. As he finishes writing this, he turns back to the students, at which point Martin looks up from his text book, orients his gaze towards the teacher and produces, in low volume, the correct present tense form bliver 'become(s)'. In overlap the teacher begins what can be heard as an extension of his previous turn, but suspends this and asks Martin to provide the present tense form (line $62 \& 64$ ). This, Martin does in next position, with a rising intonation contour, and which is subsequently accepted by the teacher.

As mentioned earlier, this extract is recorded in the first module. The classroom interaction on grammar is held in English, so obviously the expectations for the students' command of English are high - while they are low with respect to the command of the target language. Danish is not used as a language proper (i.e. in practices of communication) but is the object of teaching. In other words, there is no code switching between the target language and the lingua franca in this extract. The sequence brings to mind traditional language teaching where languages are taught as objects and 


\section{Late draft}

where rules - not use - are in focus. We see here clearly very different use and learning environments for the two languages involved. English is learned in and through use - as fitting with the pedagogical history of English in the Danish school system - any other language, however, is taught through grammar instruction and even translation.

We observe that from the teacher's production of the verb in its infinitive form, Martin has been able to project what the required next request will be: the present tense form for the verb at blive ${ }^{7}$. And Martin shows a faster pace to get to this next activity than the teacher. He takes the teacher's rising intonation in line 59 and the following silence as an implicit environment to produce the past tense form. Martin hereby shows that he is well aware of the ways in which grammar oriented teaching runs off: the teacher gives the stimulus and the student produces the revised grammatical derivation.

When not accepting Martin's suggestion as a relevant next, the teacher makes obvious that he is in charge of the order of talk in the classroom. It is not Martin's correct answer which counts but the appropriate sequential place of the correct answer in the order controlled by the teacher. Only following an addressed request in line 62 is Martin allowed to reproduce the grammatical form.

In Excerpt 1, we witness a rather traditional type of language teaching where the target language is the object of instruction. It is pedagogically traditional as well in the way the teacher enforces the order of talk and hereby makes the institutional character of this interaction visible: the teacher has the institutional right to set tasks and allocate answering slots to the students. Martin challenges this order, which the teacher subsequently re-instantiates. What is not traditional, however, is that the language of instruction is not the first language of the students or the target language, but - at least for most of them - a lingua franca of which competence is taken for granted.

\footnotetext{
${ }^{7}$ at here functions as an infinitive marker for the verb base blive
} 


\section{Late draft}

In the following extract, from an upper-intermediate class (Module $4^{8}$ ) the medium-of-interaction is Danish. In the data set, there is an overall tendency for the increased use of Danish in the more advanced classes than what we witness in the lower level classes. However, as illustrated by this example, English has not been banished altogether. In the excerpt, a student draws on his knowledge of the English infinitive verb form, to ascertain the correct Danish usage in a line from his completed homework. In this case, it is the student who introduces the equivalent English form, rather than the teacher.

Excerpt 2 Level: Module 4; TEA teacher; WEI Wei

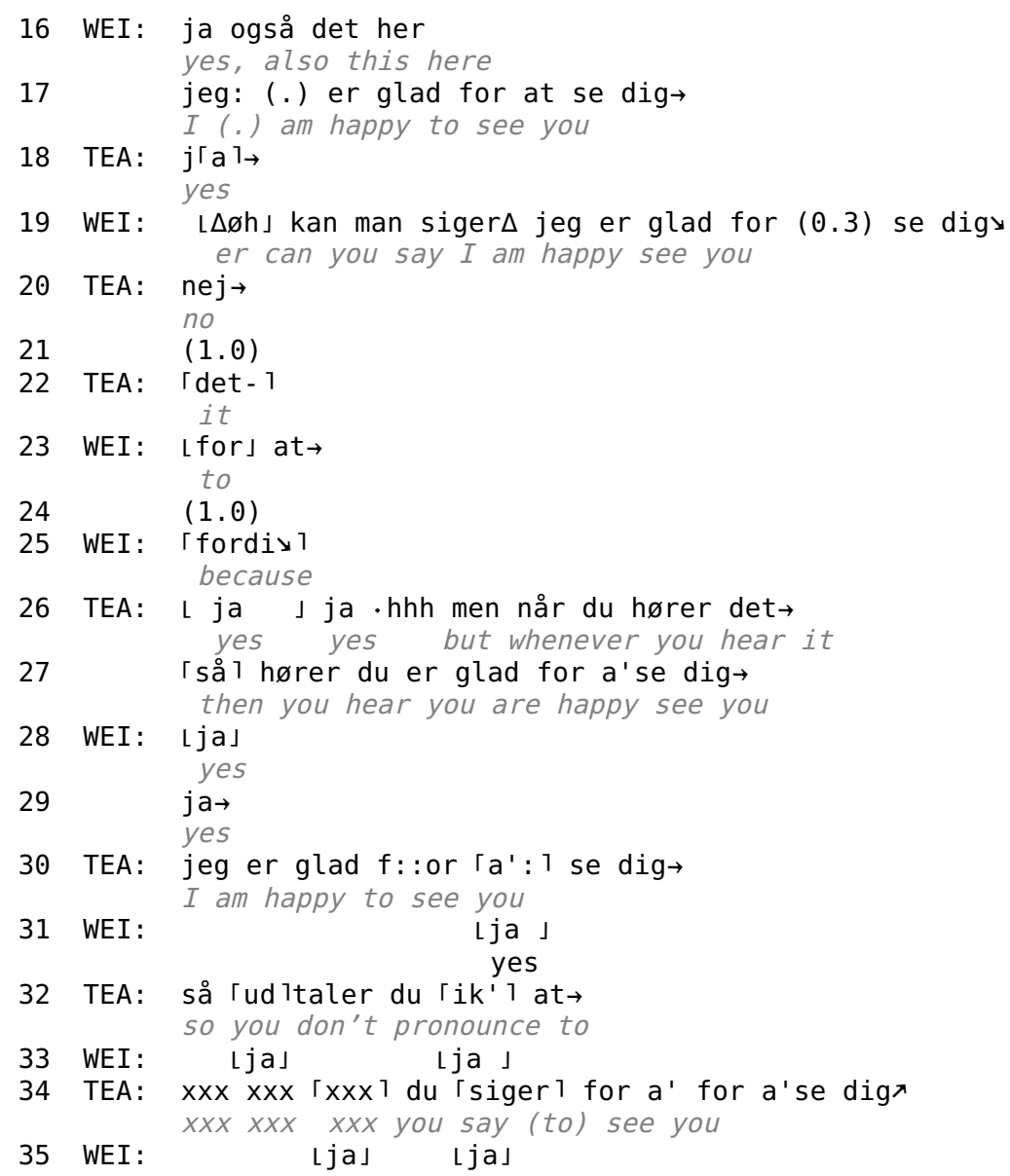

\footnotetext{
${ }^{8}$ This equates with the Threshold (B1) level of The Common European Framework of Reference for Languages (CEFR), (see www.coe.int/lang)
} 


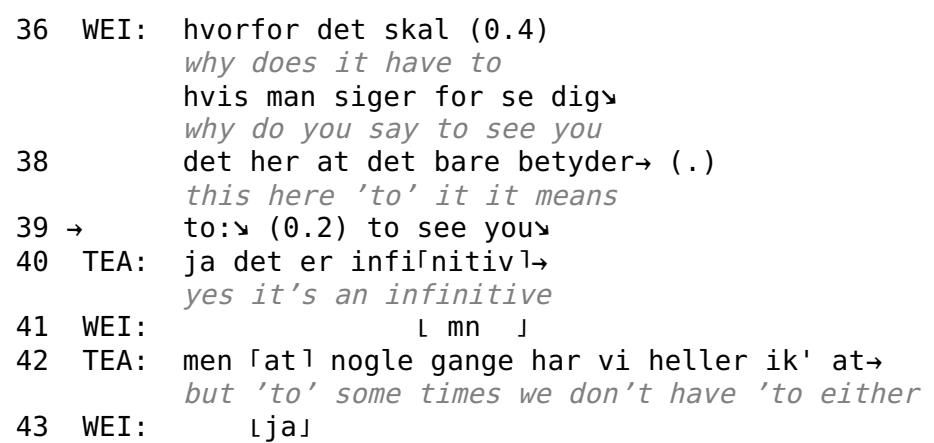

The sequence concerns the student Wei seeking to clarify a particular Danish construction, glad for + infinitive, ('happy + infinitive'). After having answered the grammatical exercise correctly (line 17) he questions whether the infinitive marker at can be dropped from the construction (here: glad for se dig 'happy see you'). The teacher responds negatively (line 20) and embarks after a second's silence on what might be an account, i.e. an explanation why this is not possible. In overlap, Wei delivers the corrected element (for at, line 23), demonstrating again that he has understood and is able to produce the correct version. The teacher acknowledges the correction (line 26) but proceeds into an account (line 26-27) that the at is uttered in a contracted form in spoken Danish, and therefore difficult or impossible to hear. The teacher goes on to demonstrate the way it would be produced in speech (in line 30 and again in 34), with further elaboration on the absence of the uttering of at in spoken Danish in line 32. However, the student returns to the initial focus introduced in line 19 and relates to the parameters of appropriate usage of the grammatical construct, rather than to a concern of spoken Danish. In line 36, he starts to formulate a request for explanation, before producing a conditional clause, with a candidate answer (lines 38, 39). The resource that he draws on here involves the introduction of a candidate equivalent construct in English (line 39), as he asks whether the at in the construct at hand equates with the English 'to' in 'to see you'. The teacher subsequently confirms this understanding. We notice that the change into 
Late draft

English is in no way accounted for by the participants. The lingua franca is treated as a resource at hand which can be used for all practical purposes.

While in Excerpt 1 the target language was talked about in the lingua franca, now Danish is the language of the talk about Danish. The role of the lingua franca as a resource for sense-making has shifted radically. In Excerpt 1, English is such an overwhelming resource that the language of the interaction changes. In Excerpt 2, Danish has replaced English, but for the purpose of comparing for understanding, the lingua franca is still a preferred resource.

\subsection{Seamless code switching between target language and lingua franca}

In the following section, we turn our attention to sequences where participants shift between the lingua franca and target language. The excerpts included are drawn from a lower intermediate level class $^{9}$. Compared to the levels featured in 2.1, it appears to be more common that English and Danish are used interchangeably as both medium-of-instruction-and-interaction. The following example illustrates this:

Excerpt 3 Level: Module 2/3; TEA teacher; AGN Agnes; BEN Benjamin; CEC Cecily; DIN Dina

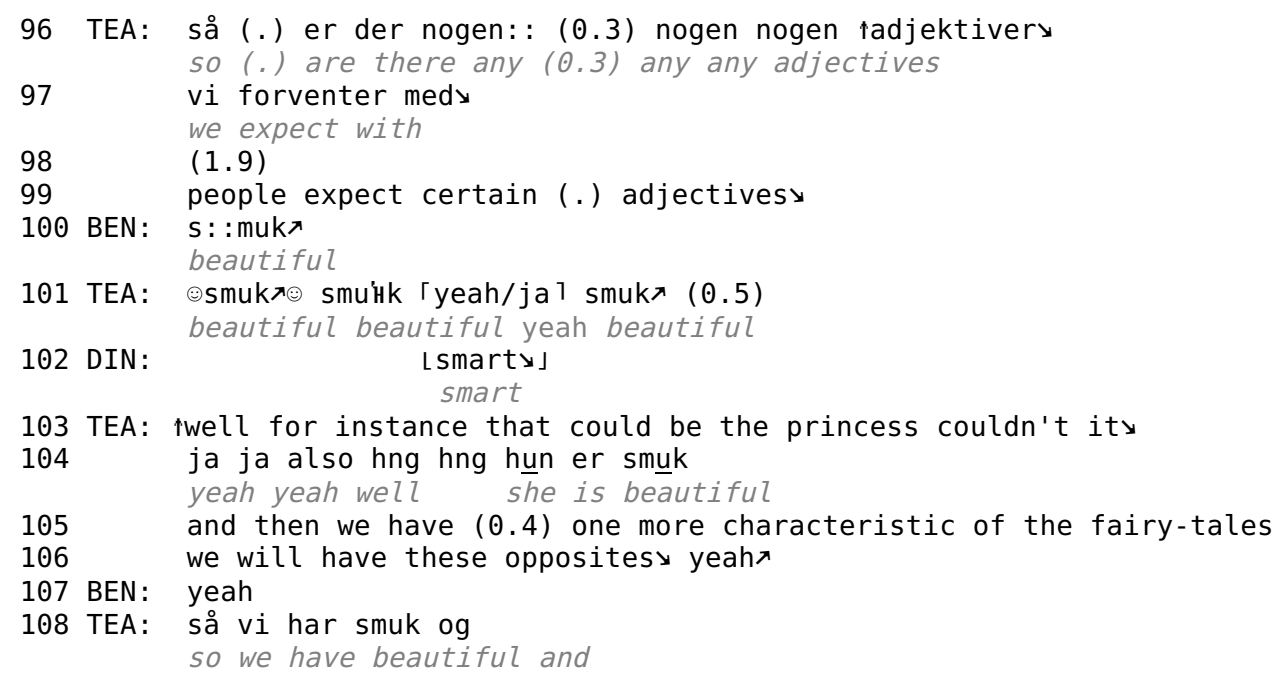

${ }^{9}$ A combined Module 2/3, equivalent to the Waystage (A2/B1) level of The Common European Framework of Reference for Languages. 


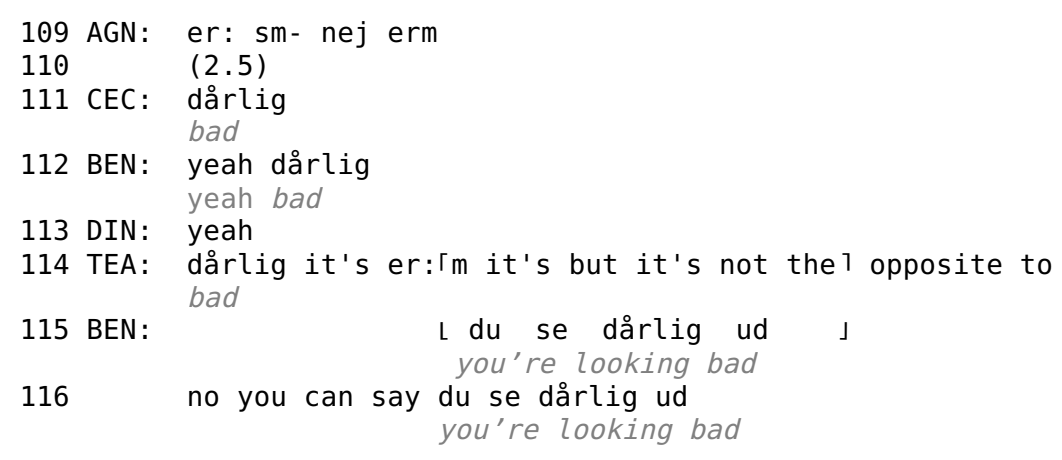

When no student responds to the teacher's rather implicit task formulation (line 96), the teacher pursues an answer by shifting into English. In the next turns, the students deliver Danish adjectives which are received by the teacher in Danish. Especially interesting are lines 103 and 104. In 103, the teacher talks about what the adjective smuk 'beautiful' could refer to and then delivers the example in Danish in line 104. In his next contribution $(105,106)$ he shifts back to English to shift again to Danish in line 108.

The shift between target language and lingua franca is seamlessly and clearly ordered. The first shift happens when the students do not respond to the task formulation in the target language. Then the teacher pursues the answer in the lingua franca, indicating that he expects no problems of understanding when using English. The examples delivered by the students are obviously Danish adjectives and they are received and contextualized in Danish while the introduction is in English c.f. for example lines 103 and 104. In lines 105 and 106 the teacher adds to the task. Now he expands the task to not only looking for adjectives but for pairs of opposite adjectives. The choice of English in lines 105/106 ties to the earlier task formulation in line 99. The environment for the expected next adjective is then delivered in Danish again (line 108) while the negative evaluation of the candidate task solution dårlig 'bad' is delivered in English again. The students follow the pattern of language shift demonstrated by the teacher. In line 116 we note that Benjamin frames the suggested Danish target form with a clarification in English. 
Language choice and alternation are dynamic and emergent properties of the interactional setting, and the languages do different local 'jobs'. The long silence in line 98 is a crucial trigger here. We see the teacher understanding the students' lack of response as their difficulty to comprehend the task formulation, and then shifting into the lingua franca while the objects of the talk are words and phrases of the target language. The teacher appears to be sensitive to possible problems of understanding and seems to follow the maxim to use as much Danish as possible and as much English as necessary to drive the work in the classroom. So the shift has its root in plain epistemic conditions. When the students do not respond to the task, the teacher orients to this as a problem of understanding and switches into the lingua franca, which is expected to provide a solution. The situation brings to mind what we have observed in Excerpt 1. The difference is that the teacher, depending on his assessment of the students' understanding in Extract 3, can shift into or out of the lingua franca.

The participants can make sense of the language shifts since they are orderly and bound to recognisable action sequences. Drawing on Seedhouse (2004), these practices are normative and reflexive frameworks, available to participants in interaction as "action template[s] for the production of their social actions and as a point of reference for the interpretation of their actions" (2004, p17). Kidwell (2000) argues that a recognizable framework of a projected course of action provides a blueprint within which interlocutors are able to co-construct understanding. Drawing on these insights, we turn now to a recurrent action sequence type, where students' lingua franca competences are activated by the teacher in the pursuit of Danish understanding.

\subsection{Clarifying Danish items through the lingua franca}

In this section, we turn to a sequence where the classroom participants produce a particularly recurrent action sequence, where the lingua franca is employed to clarify issues in the target language. 
Excerpt 4 occurs towards the end of a classroom break as teacher and students are waiting for some of the other students to return. Christina is sitting at a table making notes, when in line 57 , she looks up to the teacher and asks for the meaning of the Danish word 'emne' (Eng.: subject or topic), a word that was introduced a short time prior to the sequence. At the time, the teacher glossed the word 'emne' as 'topic' in English, orienting to the projected task of preparing a short presentation.

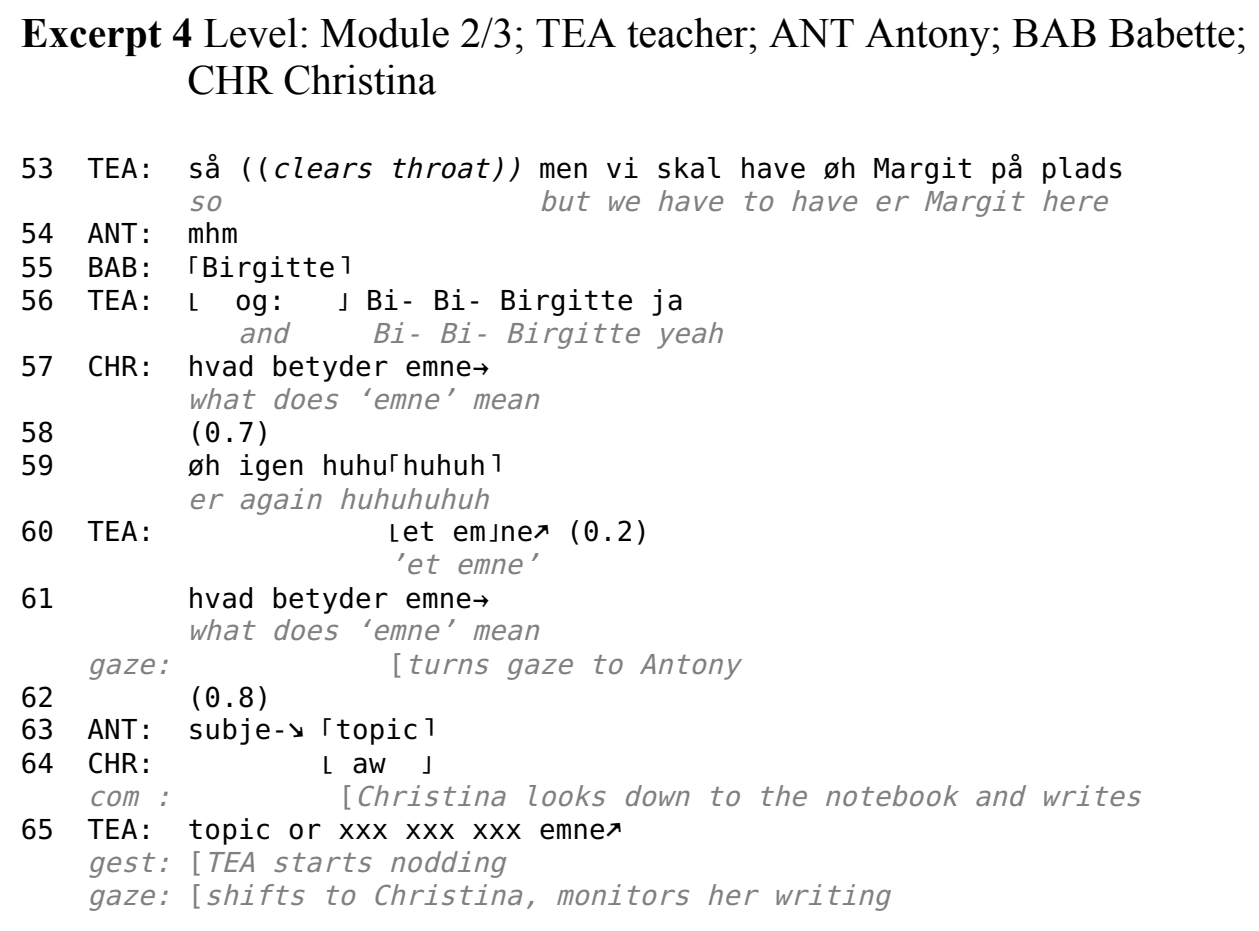

In line 57 Christina asks for the meaning of emne 'topic'. As no response is forthcoming, she adds øh igen 'uhm again' and laughter to her utterance. By igen she connects her turn to the preceding classroom interaction and indicates as well that she is supposed to have learned the word. The teacher's response is delayed and treats the question as answerable by the other students. Antony provides a candidate answer in English, first with the interrupted term 'subject', a perfectly good translation of the term, but then repairing this to 'topic', the English term that was used earlier by the teacher, when the Danish word was initially introduced and subsequently translated to English. As Antony produces the term, Christina acknowledges this with the change-of-state token 'aw', and 


\section{Late draft}

subsequently continues writing in her notepad. At the same time, the teacher also confirms Antony's answer, here with a head nod, following which he repeats the word in English, and follows this up with restating it in Danish. He then redirects his gaze to Christina, and monitors her as she makes a note on the paper in front of her.

In delivering the English translation, Antony - as Wei in Extract 2 - clarifies the meaning by using the lingua franca. Providing an equivalent form in English is treated here as an unproblematic strategy for offering a solution. However, there are some other aspects which surface in this extract.

Firstly, the restricted use of the lingua franca indicates again an orientation of the participants to maximise the use of the target language and minimize the use of the lingua franca. The participants create shifts between both languages which are locally sensitive to how the interactional competence of 'the other' is assessed.

Secondly, several different orders manifest themselves in these extracts. We already referred in the discussion of Excerpt 1 to the order of the classroom which was upheld and re-created by the teacher. In Excerpt 4, Christina asks for a gloss of a Danish word that had been in the focus of the talk a short time before. Her laughter when referring back to this earlier use of emne indicates that here is more at stake here than just a vocabulary question. Christina embellishes her increment to the question (line 59) with laughter - which indicates that not remembering what as just had been the focus of the class is a sensitive issue which touches on what Garfinkel (1964:225) has referred to as the moral order.

A society's members encounter and know the moral order as perceivedly normal courses of action - familiar scenes of everyday affairs, the world of daily life known in common with others and with others taken for granted.

Breaching normality necessitates more than accounting. It attracts attention, creates anxiety, even moral and psychological evaluations, and may threaten the status of the breacher. Christina's laughter reflects this. Not remembering an item which just has been taught is sensitive and it is 


\section{Late draft}

marked as that. This is notably different from the situation where students and teacher shift in and out of the lingua franca. Here we see no laughter or accounting for the shifts, it is just done. Just doing things are the normality created by the moral order in interaction. Drawing attention to potentially sensitive issues points at the underlying moral order and at what is handled as normal. In other words, in all our extracts in the collection, using the lingua franca does appear to be a 'natural fact of life'.

The Extract shows one particular pattern of action sequence evidenced in this data set. Here, where a particular Danish linguistic form is flagged up as problematic, the teacher subsequently enlists the students in attending to the form; a student produces a candidate equivalent form in English; the teacher ratifies this, restates the English form, and returns to the Danish. The class then resumes where it left off at the outset of the side sequence. What is pertinent to this study is that these sequences involve the teacher not only triggering the students' L2 English language competences in negotiating meaning in Danish language learning, but that the teacher indeed treats the Englishlanguage resource as the de facto means to secure understanding in the classroom. Furthermore, this requires the students to access English terms and grammatical forms by utilizing the contextual elements provided in the target Danish in order to locate the correct equivalent. The next and final extract follows the same overall structure, but is slightly different in outcome, as students here operate in the lingua franca on finding the meaning of a target language word.

Excerpt 5 Level: Module 2/3; TEA teacher; BOB Bob; CEC Cecily; DIN Dina (simplied)

63 TEA: en præsentation det er første dagspunkt

a presentation that's the first point on the agenda

$(0.6)$

øhm (0.2) og så er der noget der hedder (0.2) forskningsprojekt $\rightarrow$

erm (0.2) and then there is something called (0.2) research project $\rightarrow$

$(1.6)$

projekt kender $i \rightarrow$

project you know $\rightarrow$

BOB: $\lceil\mathrm{mhm} 1$

CEC: $\lfloor\mathrm{mhm}\lrcorner$ 


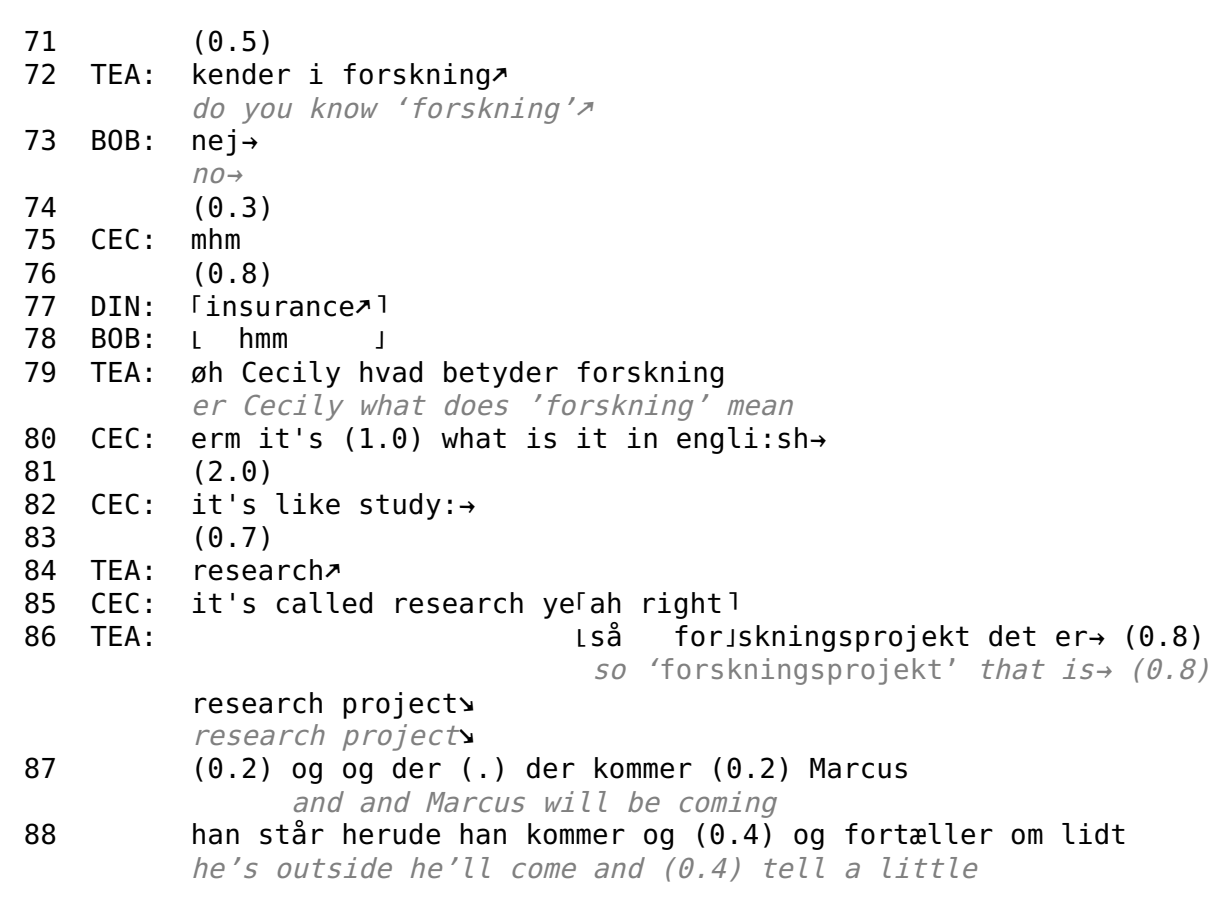

Again, as in the earlier examples, we see that this sequence follows a similar pattern, with a problematic Danish term requiring resolution in the locating of an English equivalent. The term forskningsprojekt 'research project' is introduced in line 65, and again the format in which this turn is produced projects that there is trouble involved with the term. The item is preceded by the existential construction så er der noget der hedder 'there is something called', which acts to project that the upcoming element may be unfamiliar to the recipient (for discussion, see Svennevig, 2010), and a 0.2 pause immediately prior to the term. The teacher produces a pointing gesture to one lexical component in the term, projekt, and suggests it is unproblematic, which is ratified in next position by both Bob and Cecily. He subsequently turns to the initial component in the lexical construction, forskning 'research', producing a second finger point at the centre of the word, and asking kender i forskning 'do you know research.' This is done again with rising intonation, upon which he redirects his gaze to the students. 
In response to the teacher's question, several students respond, albeit each different in nature. Bob answers in the negative (line 73); Cecily, in contrast, answers in the affirmative, while Dorothea produces a candidate term in English, 'insurance ${ }^{10}$. Cecily's response leads to the teacher selecting her to shed light on the term in line 79 , and she proceeds to attempt to do so. Interestingly Cecily switches immediately into the lingua franca and produces her reasoning work in English ('what is it in English'). As in the earlier examples, English seems to be a generally good resource for sensemaking, here demonstrably the default resource for Cecily. She prefaces the response with a hesitation marker ('erm'), which appears to project at this point already upcoming trouble, and suspends the subsequent turn almost immediately. The English equivalent appears to not be readily at hand, and Cecily initiates a word search activity (Goodwin \& Goodwin, 1986, Brouwer 2003). Interestingly, her request for assistance ("what is it in English", line 80) is not only formulated in English, but refers specifically to English being the relevant language through which to respond to the teacher's question. When no help is forthcoming from the teacher or the other students (note the 2 second pause in line 81), Cecily pursues the word search with a turn extension when she introduces a synonymous word, while marking it as not constituting the target item ("it's like study"). Following another 0.7 second pause, the teacher offers 'research' as a candidate for the term she is looking for, produced with rising intonation, and Cecily confirms this in next position. The manner in which the teacher gets Cecily to provide confirmation of the candidate term, rather than simply providing the term itself (for example by formatting it with falling intonation) appears to orient to the organization of this type of action sequence, where it should be the students who ultimately provide the answer, with the teacher then confirming then this. Following Cecily's confirmation of the ratification of his suggested term, the teacher then reconstitutes the full term "forskningsprojekt" (line 86), and subsequently provides the English equivalent for the full noun

\footnotetext{
${ }^{10}$ The Danish word for insurance is forsikring, which as we see somewhat resembles forskning
} 


\section{Late draft}

phrase. Once this has been done, he returns to where they left off, discussing the agenda for the class (line $87 \& 88)$.

This sequence differs from the ones described earlier in that it requires the student(s) to draw on other competences than 'simply' accessing their L2 English vocabulary or knowledge of English grammar and retrieving equivalent linguistic forms in English. They are here required to engage in negotiation sequences, projecting word search sequences, enlisting the help of others, proposing synonymous terms, contextualizing the target referent, and rejecting or confirming others' suggestions. One language choice available to them is to do this in the designated classroom lingua franca.

\section{Discussion}

Although L2 classrooms have been studied extensively as settings where language learning is occasioned, the focus has been overwhelmingly on language learning, interaction and competences in the target language of the course (for example, Seedhouse, 2004; Mori, 2004; Mondada \& Pekarek Doehler, 2004; Cekaite, 2007). The student cohorts in these studies often also share similar sociocultural backgrounds and a shared first language. What is different in the current study is that both the target language, here Danish, and the lingua franca medium through which the pedagogical activities are carried out, here English, are foreign languages for the overwhelming majority of the students ${ }^{11}$. As a result, the students are often required to attend to two additional languages concurrently, across different types of activity sequences in the classroom, including classroom management, task-focused activities, and form-focused instruction.

That students in a Danish second language class both use their lingua franca, English, to conduct interactions, and locate equivalent target forms in that language also, suggests that these settings offer students not only opportunities for language development in the target language, but also

\footnotetext{
${ }^{11}$ One of the authors, himself a L1 user of English, was also a student in one of the classes recorded for this data set.
} 


\section{Late draft}

further opportunities for incidental development in the lingua franca. The analysis demonstrated how students' competences in their lingua franca English are drawn on as a resource through which to pursue understanding of particular target structures in Danish. Participants here bring their knowledge of grammatical forms of English to bear on the pursuit of securing and/or displaying understanding of equivalent structures in the target language, Danish (Excerpts $1 \& 2$ ). The data evidences how English is treated, by teachers and students alike, as a legitimate resource in the Danish language classroom, for negotiating understanding of equivalent, or divergent, formal linguistic structures in Danish.

We observed also how classroom participants orient to the production of a particular recurrent action sequence, where English is treated as the de facto solution sought after in side sequences where a form-focused activity is occasioned. These sequences are initiated by either student or teacher, and involve the pursuit of equivalent Danish forms in English. The teacher can nominate students to provide explanations of particular formal linguistic target items through recourse to their knowledge of equivalent forms in the designated classroom lingua franca, English (Excerpts 3 \& 4), as well as further interactional competences where the target form cannot be immediately accessed

\section{(Excerpt 5).}

Finally, in the introduction we discussed how a student mobility programme such as the EU's ERASMUS framework aims for the development of "well-qualified, open-minded and internationally experienced" future professionals (European Commission, 2012a:3), with knowledge of other cultures and languages, deemed vital experience for further career opportunities (European Commission, 2012b). Transnational mobility is not of course limited to students, and in an increasingly globalized professional marketplace, the likelihood of these students encountering in their professional lives equally international, and linguistically dynamic workplace settings has never been greater. These may feature equivalent lingua franca engagements and, even though 


\section{Late draft}

English is often heralded as a one size fits all solution, other languages in the overall mix. In such a case, the idealized monolingual native speaker model so popularized across large swathes of L2 education (e.g. Firth \& Wagner 1997) would play second fiddle to a competent multilingual model associated with a transnational identity, of someone able to operate across a number of languages. We would suggest that this latter model is developed much more strongly in the classroom practices described for this particular transnational setting, where members' different linguistic repertoires give rise to the use of a lingua franca. The teacher here provides the students with a role model of being a competent multilingual, and legitimates the student's drawing on her or his alternative linguistic repertoires in the pursuit of understanding. An ability to operate in more than one language is here a key feature.

CA studies of L2 interaction suggest that where participants do not share the same linguistic background or resources, we see evidence of competent interlocutors not so much re-specifying normative interactional practice, but at least adopting more flexible orientations to what may be treated as orderliness (for example, Firth, 1996; Wong, 2004). Hazel \& Mortensen (2013: 27) argue that this requires of participants that they develop the interactional competences to be able to adapt to the local, international, make-up of the particular engagement frameworks to which they are party:

The sensitivities involved in managing such emergent engagement frameworks require of members that they develop interactional competencies which enable them to recognize and respond appropriately to shifting patterns of normativity, not least as far as language choice is concerned.

These inquiries demonstrate that 'membership' may also be displayed in an ability to adapt to dynamically emergent, ever-fluctuating norms and practices as socially situated activities are negotiated by participants-in-interaction. In the case at hand, membership in this particular 
Late draft

classroom setting, the interactional competences to manage ongoing fluctuations in language choice are contingent features of the social identity construct doing-being-a-competent-multilingual.

\section{APPENDIX Transcription conventions}

The transcription conventions are based on those developed by Gail Jefferson (e.g. 2004). Some are used in modified form for use in the CLAN software tool (MacWhinney \& Wagner 2011).

Identifier

Pause

Overlap markers top

Overlap markers bottom

Intonation: rising

continuing
falling

Pitch shift

Latched turns

Smiley voice

Unsure

Within word laughter

Inbreath

Stress

Accelerated speech

Translation
TEA :

$(0.2)$

Г 1

L 」

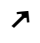

$\rightarrow$

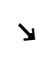

$\uparrow$

$\approx$

(-)

æWUnsure?

'H

- hhhh

now

$\Delta$ and you $\Delta$

In italics

\section{List of References}


Late draft

Bonacina, F. \& Gafaranga, J. (2011). 'Medium of instruction' vs. 'medium of classroom interaction': language choice in a French complementary school classroom in Scotland. International Journal of Bilingual Education and Bilingualism 14(3) 319-334

Brooks, R., Fuller, A., \& Waters, J. (Eds.). (2012). Changing Spaces of Education: New Perspectives on the Nature of Learning. Abingdon: Routledge.

Brouwer, C. E. (2003). 'Word searches in NNS-NS interaction: Opportunities for language learning?' The Modern Language Journal 87/4: 534-45.

Cekaite, A. (2007). A child's development of interactional competence in a Swedish L2 Classroom. The Modern Language Journal 91/1: 45-62.

Eskildsen, S.W \& Wagner, J. (2013). Recurring and shared gestures in the L2 classroom: Resources for teaching and Learning. European Journal of Applied Linguistics 1(1): 1-23

European Commission (2012a). Speaking for Europe. Retrieved from http://ec.europa.eu/education/languages/pdf/doc3275_en.pdf

European Commission (2012b). Erasmus - Facts, Figures \& Trends. The European Union support for student and staff exchanges and university cooperation in 2010-11. Retrieved from http://ec.europa.eu/education/pub/pdf/higher/erasmus1011_en.pdf

Firth, A. (1996). The discursive accomplishment of normality: On conversation analysis and 'lingua franca' English. Journal of Pragmatics, 26, 237-259.

Firth, A. \& J. Wagner (1997). On discourse, communication, and (some) fundamental concepts in SLA. Modern Language Journal 81 (3): 285-300.

Garfinkel, Harold. 1964. Studies of the routine grounds of everyday activities. Social Problems, Vol. 11, No. 3 (Winter, 1964), pp. 225-250 
Late draft

Goodwin, C. (1995). Seeing in Depth. Social Studies of Science, 25(2), 237-274.

Goodwin, M. H., \& Goodwin, C. (1986). Gesture and coparticipation in the activity of searching for a word. Semiotica, 62(1/2), 51-75.

Haberland, H., Mortensen, J., Fabricius, A., Preisler, B., Risager, K., \& Kjærbeck, S. (Eds.). (2008). Higher Education in the Global Village: Cultural and Linguistic Practices in the International University. Roskilde: Roskilde University, Department of Culture and Identity

Hazel, S. (2012). Interactional competence in the institutional setting of the international university. Ph.d. thesis. Roskilde: Roskilde University

Hazel, S., \& Mortensen, J. (2013). Kitchen talk - Exploring linguistic practices in liminal institutional interactions in a multilingual university setting. In H. Haberland, D. Lønsmann \& B. Preisler (Eds.), Language alternation, language choice and language encounter in international education. Dordrecht: Springer.

Hellermann, J. (2008). Social actions for classroom language learning. Clevedon: Multilingual Matters.

Jefferson, G. (2004). Glossary of transcript symbols with an introduction. In G. Lerner (Ed.) Conversation Analysis. Studies from the First Generation. (pp. 13-32. Amsterdam: John Benjamins.

Kasper, G. (2004): Participant orientations in German conversation-for-learning. The Modern Language Journal, 88 (4), 551-567.

Kidwell, M. (2000). Common Ground in Cross-Cultural Communication: Sequential and Institutional Contexts in Front Desk Service Encounters. Issues in Applied Linguistics, 11(1).

Kirkebæk, M. (2013). "Teacher! Why do you speak English?” A Discussion of Teacher use of 
Late draft

English in a Danish Class. In H. Haberland, D. Lønsmann \& B. Preisler (Eds.), Language alternation, language choice and language encounter in international education. Dordrecht: Springer.

Knight, J. (2004). Internationalization remodeled: Definition, approaches, and rationales. Journal of Studies in International Education, 8(1), 5-31.

Lasagabaster, D. (2008). Foreign language competence in content and language integrated courses. The Open Applied Linguistics Journal, 1, 31-42.

Lee D-Y. \& Ogi, N. (2013). English as a Lingua Franca: A Case of Japanese Courses in Australia. In H. Haberland, D. Lønsmann \& B. Preisler (Eds.), Language alternation, language choice and language encounter in international education. Dordrecht: Springer.

MacWhinney, B., \& Wagner, J. (2010). Transcribing, searching and data sharing: The CLAN software and the TalkBank data repository. Gespraechsforschung, 11, 154-173.

Markee, N. (1995). Teachers' answers to students' questions: Problematizing the issue of meaning making. Issues in Applied Linguistics, 6, 63-92.

Markee, N. (2000). Conversation analysis. Mahwah, NJ: Erlbaum.

Markee, N., \& Seo, M.-S. (2009). Learning talk analysis. International Review of Applied Linguistics in Language Teaching, 47, 37-64.

Mori, J. (2004). Negotiating Sequential Boundaries and Learning Opportunities- A Case from a Japanese Language Classroom. The Modern Language Journal, 88, iv, 536-550

Mortensen, J. (2010) Epistemic stance marking in the use of English as a lingua franca. $\mathrm{PhD}$ thesis. Roskilde University.

Mortensen, J. (in press, 2014) Language policy from below: Language choice in student project 
Late draft

groups in a multilingual university setting. Journal of Multilingual \& Multicultural Development.

Mortensen, J. \& Haberland, H. (2012). English - the new Latin of the elites? Danish universities as a case. International Journal of the Sociology of Language 216

Mondada, L. \& Pekarek Doehler, S. (2004). 'Second language acquisition as situated practice: Task accomplishment in the French second language classroom,' Modern Language Journal 88/4: 501-18.

OECD. (2012). Education at a Glance 2012: OECD Publishing.

Preisler, B., Fabricius, A., Haberland, H., Kjærbeck, S., \& Risager, K. (Eds.). (2008). The Consequences of Mobility. Roskilde: Roskilde University, Dept. of Culture and Identity.

Sacks, H., Schegloff, E. A, \& Jefferson, G. (1974). A simplest systematics for the organization of turn-taking for conversation. Language, 50, 696-735.

Seedhouse, P. (2004). The interactional architecture of the language classroom : a conversation analysis perspective. Malden, MA: Blackwell Pub.

Svennevig, J. (2010). Pre-empting reference problems in conversation. Language in Society 39, 173-202

Waters, J., \& Brooks, R. (2012). Transnational spaces, international students: emergent perspectives on educational mobilities. In R. Brooks, A. Fuller \& J. Waters (Eds.), Changing Spaces of Education: New Perspectives on the Nature of Learning (pp. 21-38). Abingdon: Routledge.

Wang, D. (2013). The Use of English as a Lingua Franca in Teaching Chinese as a Foreign Language: A Case Study of Native Chinese Teachers in Beijing. In H. Haberland, D. Lønsmann \& B. Preisler (Eds.), Language alternation, language choice and language encounter 
in international education. Dordrecht: Springer.

Wong, J. (2004). Some preliminary thoughts on delay as an interactional resource. In R. Gardner \& J.

Wagner (Eds.), Second Language Conversations: Bloomsbury.

An idealised model of an English native speaker has occupied a central position in English L2 pedagogy for considerable time. Regardless of the issue that this presents language learners with a target model that is at best irrelevant, or even undesirable, L2 classroom materials and cohorts of teaching staff engaged in English language teaching, often feature stubbornly monolingual role models that students are deemed to aspire to emulate. The changing sociolinguistic landscape that has resulted from increased globalisation, with English adopted as a lingua franca across a wide range of social settings in non-Anglophone countries, foregrounds the importance of rethinking which role models are suitable and appropriate to present to L2 students.

- Discuss the relative merits of the L1 native speaker role model and that of the competent multilingual.

- In which situations would it be beneficial for students to focus on the L1 monolingual native speaker as primary relevant construct? In which the competent multilingual, able to combine resources drawn from different linguistic systems?

- Which model would be most relevant for your own teaching and your students?

This chapter suggests that students here engage in joint Danish and English language focus activities during these classes, one in a conventional understanding of language pedagogy, foregrounding language learning as explicit input of linguistic systems, the other through the use of an L2 in problem solving sequences and other interactional environments (e.g., classroom management, off-task talk).

- Providing students with authentic materials, tasks and activities has long been considered desirable for L2 classroom engagement. How authentic are the relative tasks encountered and negotiated in the data described here?

- What opportunities does this suggest for language tasks in the L2 classroom?

\section{Suggested readings:}

Haberland, Lønsmann \& Preisler (eds.). (2013). Language Alternation, Language Choice and Language Encounter in International Tertiary Education. Dordrecht: Springer

This volume gathers together a large number of studies carried out at universities worldwide, teasing out the implications of the modern, globalised age for the multilingual realities of those living, studying and working in these dynamic settings. Relevant to this chapter is also the focus on how English used as a lingua franca coexists with other languages, as participants go about their engagements with other transnationally mobile parties to these institutional settings. 
Late draft

Hall, Hellerman \& Pekarek-Doehler (eds). (2011). L2 Interactional Competence and Development. Multilingual Matters.

Pallotti \& Wagner (eds.). (2011). L2 Learning as Social Practice: Conversation-Analytic Perspectives. Honolulu: NFLRC

Two volumes that are relevant in how they foreground the social, rather than cognitive, implications in L2 learning. The studies presented here apply conversation analytic methods to data where there is an orientation to language learning, either in or away from the classroom. 